\title{
A Comparative Study of Spark Plasma and Conventional Sintering of Undoped $\mathrm{SnO}_{2}$ Sputtering Targets
}

\section{Levent Koroglu}

Eskişehir Technical University: Eskisehir Teknik Universitesi

\section{Cem Aciksari}

Eskişehir Technical University: Eskisehir Teknik Universitesi

\section{Erhan Ayas ( $\nabla$ erayas@eskisehir.edu.tr)}

Eskişehir Technical University: Eskisehir Teknik Universitesi

\section{Emel Ozel}

Eskişehir Technical University: Eskisehir Teknik Universitesi

\section{Ender Suvaci}

Eskişehir Technical University: Eskisehir Teknik Universitesi

\section{Research Article}

Keywords: SnO2, Spark Plasma Sintering, Conventional Sintering, Undoped, Sputtering Targets

Posted Date: June 24th, 2021

DOl: https://doi.org/10.21203/rs.3.rs-646052/v1

License: (c) (i) This work is licensed under a Creative Commons Attribution 4.0 International License. Read Full License 


\section{Abstract}

$\mathrm{SnO}_{2}$ ceramics were fabricated by spark plasma sintering (SPS) and conventional (pressureless) sintering techniques by using undoped submicron $\mathrm{SnO}_{2}$ powders. The effect of sintering temperature and dwell time on the densification behavior, phase evolution and microstructural development of sintered ceramics were investigated. The relative density of SPSed ceramics increased when dwell time was raised from 1 to $10 \mathrm{~min}$ at $950^{\circ} \mathrm{C}$. However, full densification was prevented by the decomposition of $\mathrm{SnO}_{2}$ to $\mathrm{Sn}$ and $\mathrm{O}_{2}(\mathrm{~g})$. The decomposition starts after $\sim 10 \mathrm{~min}$ at $950^{\circ} \mathrm{C}$. In parallel to this observations, as sintering temperature increases, amount of the elemental $\mathrm{Sn}$ in agglomerated form increases. On the other hand, the relative densities of conventionally sintered ceramics (at $1200^{\circ} \mathrm{C}-1400^{\circ} \mathrm{C}$ ) were relatively low (i.e., 63 \% relative density), and abnormal grain growth was observed due to the shift in sintering mechanisms to evaporation-condensation as a dominant mechanism. Since the undoped $\mathrm{SnO}_{2}$ ceramics, SPSed at $950^{\circ} \mathrm{C}$ for 5 min under $30 \mathrm{MPa}$ exhibit $93 \%$ relative density, high chemical purity, homogeneous grain size distribution and smaller average grain size, they demonstrate great potential as sputtering targets for production of high-quality thin film gas sensors.

\section{Introduction}

Tin oxide $\left(\mathrm{SnO}_{2}\right)$ is a critical electronic material which has been widely used in an extensive range of applications such as gas sensor [1], varistor in electronic devices [2], electro/photocatalyst [3, 4], transparent conductive oxide films [5] and optoelectronic devices [6]. The most important application field of $\mathrm{SnO}_{2}$ material is in metal oxide semiconductor (MOS) based gas sensors. The MOS sensors are the most preferred and currently used devices among the other sensing mechanisms such as catalytic, electrochemical, and NDIR (Non-Dispersive Infrared) types to detect the pollutant gases $\left(\mathrm{CO}, \mathrm{CO}_{2}, \mathrm{NO}_{\mathrm{x}^{\prime}}\right.$ $\mathrm{SO}_{\mathrm{x}}, \mathrm{VOC}_{\mathrm{s}}$ etc.) results in diminishing the air quality.

$\mathrm{SnO}_{2}$ based materials can be deposited into the gas sensing devices in the form of thick or thin films [7]. Thick films are composed of porous $\mathrm{SnO}_{2}$ in a thickness of 1 to 10 microns produced from the slurry form. Thin films, on the other hand, have a thickness of $10 \mathrm{~nm}$ to 1 micron. Several methods were used to prepare $\mathrm{SnO}_{2}$ based gas sensors, such as thermal evaporation [8], dip and spin coating [9], and hydro/solvothermal method $[10,11]$. For industrial aspects, sputtering is a widely accepted route for preparing $\mathrm{SnO}_{2}$ thin films used in gas sensing applications among these methods. Sputtering process can be performed from either metallic or ceramic targets. Ceramic targets are preferred to produce thin films with higher quality and reproductively. They have homogeneous optical and electrical properties along with the material, whereas the metallic one is cheaper and more accessible in the market and has higher thermal conductivity. One of the well-known problems during sputtering is the formation of nodules on the target material $[12,13]$. The nodules formed by the arching during the sputtering can result in the uncontrolled highly defective film. The arching is mainly related to the non-homogeneity in the chemical, physical, microstructural, and electrical properties of the sputter target. In addition to that, inhomogeneous grain size, a minimum amount of pores and higher density prevent the formation of 
nodules. The formation of particles during the sputtering process is one of the significant problems which originate from nodules on the target surface. To overcome the nodule and related causes during the sputtering process, target material should be manufactured with higher density $\left(>92 \%\right.$ of $\mathrm{SnO}_{2}$ relative density ), higher chemical purity (>99.95 wt.\% of $\mathrm{SnO}_{2}$ ), homogeneous distribution of cations and oxygen mainly in the surface and higher thermal and mechanical stability to reduce the chance of target cracking. Even ceramics with a density of greater than $98 \%$ of its relative density and high electrical conductivity are strongly required for DC magnetron sputtering systems employed in the industry [14].

It is crucial to produce dense $\mathrm{SnO}_{2}$ sputtering targets with homogenous grain size distribution and high chemical purity which provides low electrical resistivity and high thermal and mechanical stability due to getting relatively higher performance in the sputtering process. However, it is difficult to achieve full densification by pressureless-assisted sintering due to the decomposition of $\mathrm{SnO}_{2}(\mathrm{~s})$ to $\mathrm{SnO}(\mathrm{g})$ above $1200^{\circ} \mathrm{C}$ where evaporation-condensation takes place [15]. Therefore, it is concluded with only coarsening of tin oxide ceramics with very low densification (60\% relative density) [14]. Leite et al. [16] investigated pressureless-assisted sintering kinetics of ultrafine undoped $\mathrm{SnO}_{2}$ powder under atmospheric conditions. The results showed that the decomposition rate of $\mathrm{SnO}_{2}$ increases above $1300^{\circ} \mathrm{C}$ with the decreasing particle size of starting $\mathrm{SnO}_{2}$ powder (from approximately 100 to $25 \mathrm{~nm}$ ).

Possible technique to produce tin oxide-based ceramics with a higher density is pressure-assisting sintering [14]. Spark plasma sintering (SPS, FAST) is one of the most favorable sintering techniques in which dense polycrystalline materials are produced in bulk form through powder metallurgy under applied pressure. In comparison with the conventional methods and other sintering techniques such as hot press (HP) and hot isostatic pressing (HIP), SPS is fundamentally different in terms of working principle, which is based on the generation of high pulsed electric current. Thus, both electrical field and joule heating are provided along with uniaxial pressure. This phenomenon comes with some advantages such as; high-speed diffusion, full densification, elimination of impurities on the surface of particles, reduction of sintering temperature, shorting of sintering time, and improving mechanical and electrical properties [17-19].

A few types of research in the literature focus on the pressure-assisted sintering of undoped $\mathrm{SnO}_{2}$ powders. Yoshinaka et al. [20] achieved $99.8 \%$ relative density by Hot Isostatic Pressing at $900^{\circ} \mathrm{C}$ for $2 \mathrm{~h}$ under $196 \mathrm{MPa}$ using argon gas following by isostatically cold pressing of synthesized undoped $\mathrm{SnO}_{2}$ powders under $343 \mathrm{MPa}$. Dense $\mathrm{SnO}_{2}$ ceramic has $10^{3} \mathrm{ohm} . \mathrm{cm}$ electrical resistivities and approximately $2.0 \mu \mathrm{m}$ average grain size, as determined by a linear intercept method. In 2005, Park et al. [21] focused on the spark plasma sintering of undoped $\mathrm{SnO}_{2}$ powders using commercial undoped $\mathrm{SnO}_{2}$ powder $(60 \mathrm{~nm}$ crystallite size), and they investigated the variation of the relative density and the weight loss with the sintering temperature. It is reported that weight loss began to occur above $1050^{\circ} \mathrm{C}$. The sintered ceramic by spark plasma sintering at $1050^{\circ} \mathrm{C}$ for $5 \mathrm{~min}$ under $37.5 \mathrm{MPa}$ exhibited the maximum relative density (around $95 \%$ ). That is the only study in the literature based on the spark plasma sintering of undoped $\mathrm{SnO}_{2}$ powders. Unfortunately, the decomposition of $\mathrm{SnO}_{2}$ did not discuss in detail; there was no data 
regarding the phase evolution and microstructural development. Park et al. only focused on the microstructure analysis of $\mathrm{SnO}_{2}$ ceramic sintered at $1050^{\circ} \mathrm{C}$ in terms of the formation of pores and the homogeneity of microstructure. Delorme et al. [22] stated that undoped $\mathrm{SnO}_{2}$ ceramics were produced by SPS in order to improve transport properties that are sensitive to doping elements of oxides $\left(\mathrm{CoO}, \mathrm{MnO}_{2}\right.$, $\mathrm{CuO}, \mathrm{ZnO}$, etc.). In this study, they achieved almost $95 \%$ relative density at $950^{\circ} \mathrm{C}$ for 10 min under 100 $\mathrm{MPa}$. Delorme et al. mainly focused on the electrical and thermal conductivity of $\mathrm{SnO}_{2}$ ceramics, which were obtained at different SPS conditions. However, this study does not reflect detailed microstructural development among thermodynamical approaches to understand densification behaviour of $\mathrm{SnO}_{2}$ ceramics under SPS conditions. A correlative assessment of chemical purity, density, homogenously distributed grains, and small grain size of sputtering targets is crucial to both investigate and improve the performance of sputtering targets. To eliminate this shortage in the literature, in the present study, it is aimed to develop a fundamental understanding of defining ideal microstructure and its effect on final target properties based on densification behavior, phase evolution, and microstructural development in order to get higher performance and efficiency during the sputtering process and achieve higher quality of as-produced thin films as well. Therefore, in this paper, the effects of process conditions on densification behavior, phase evolution and microstructural development of $\mathrm{SnO}_{2}$ ceramic sputter targets obtained from undoped submicron commercially available $\mathrm{SnO}_{2}$ powders were systematically investigated as a function of sintering temperature $\left(850-1050^{\circ} \mathrm{C}\right)$ and time $(1-10 \mathrm{~min})$, while the particle size of starting powder, external pressure, atmospheric conditions, and heating \& cooling rates keep constant. Furthermore, the results obtained from SPSed ceramics were compared to conventionally sintered $\mathrm{SnO}_{2}$ ceramics and commercial $\mathrm{SnO}_{2}$ targets.

\section{Experimental Procedures}

\subsection{Characterization of the starting powder}

Specific surface area of the commercially available tin (IV) oxide $\left(\mathrm{SnO}_{2} ; 99.9 \%\right.$; Merck KGaA) submicron powder was measured by Brunnauer-Emmett-Teller (BET) surface adsorption method (Quantacrom Autosorb 1C). The sample was degassed at $200^{\circ} \mathrm{C}$ for $4 \mathrm{~h}$ under vacuum conditions prior to the measurement. The average particle size (i.e., equivalent spherical diameter), assuming that the particle is spherical and nonporous, was calculated from the BET surface area via equation (SS $=6 / \rho . D$ where $S S$ is specific surface area of the particles in $\mathrm{m}^{2} / \mathrm{g}, \rho$ is theoretical density of the particle and $D$ is the particle size).

The qualitative phase analysis was performed using an x-ray diffractometer (XRD; MiniFlex600, Rigaku). Particle size and distribution were measured using a scanning electron microscope (SEM; Supra 50VP, Zeiss).

Chemical purity of the $\mathrm{SnO}_{2}$ was determined by x-ray fluorescence (XRF, Rigaku ZSX Primus). 


\subsection{Sintering of undoped $\mathrm{SnO}_{2}$ ceramics}

Densification of $\mathrm{SnO}_{2}$ submicron powder without any sintering additive was achieved using spark plasma sintering furnace (HPD-50, FCT GmbH, Germany) under a vacuum atmosphere. The process parameters such as sintering temperature and holding time were optimized to fabricate dense $\mathrm{SnO}_{2}$ ceramics. During all sintering cycles, heating rate $\left(200^{\circ} \mathrm{C} / \mathrm{min}\right)$, cooling rate (switching power off, approximately $\left.600^{\circ} \mathrm{C} / \mathrm{min}\right)$, and external pressure (30 MPa) were kept constant. 4 grams of powder were loaded into a graphite die with an inner diameter of $20 \mathrm{~mm}$. Graphite foil was incorporated on the inner surface of graphite die to prevent the reaction between the graphite die and powder. The temperature was increased by the controlled electrical current with the pulse timing of 12:2, and it was monitored by optical pyrometer inside the graphite punches. In order to compare spark plasma sintering with conventional sintering technique, undoped $\mathrm{SnO}_{2}$ ceramics were also sintered by presureless method (Carbolite Lab Furnace) under conditions $\left(1200^{\circ} \mathrm{C}, 2 \mathrm{~h}, 1 \mathrm{~atm}, 5^{\circ} \mathrm{C} / \mathrm{min}\right)$ optimized in a prior study [23]. The samples with $50 \mathrm{~mm}$ diameter were prepared via uniaxial pressing under $200 \mathrm{MPa}$ for conventional sintering.

Using the submicron starting powder lieS in its high specific surface area and high surface curvature, which improve the sintering rate. Henrring equation explains well the importance of particle size on densification. For instance, when the particle size is 2 times higher, the sintering time is 16 times, where the grain boundary diffusion is dominant [24, 25]. Leite et al. [16] investigated the grain growth kinetics of nanometric undoped $\mathrm{SnO}_{2}$ powder in the temperature range of $500-1300^{\circ} \mathrm{C}$. Experimental results showed that the mass transport mechanism was controlled by surface diffusion between $500-1000^{\circ} \mathrm{C}$. The thermodynamic driving force for sintering is the reduction in total interfacial energy by diffusion. The differences in bulk pressure, vapor pressure, and vacancy concentration depending on interface curvature yield material transport in terms of kinetics [24]. Different mass transport mechanisms occur during sintering, such as lattice diffusion, grain boundary diffusion, surface diffusion, viscous flow, and gasphase transport. Some of these sintering mechanisms contribute to densification, whereas others (e.g. surface diffusion) lead to grain growth without densification, which are called non-densifying mechanisms. The dominant densification mechanism depends on experimental and compact conditions such as particle size, neck radius, temperature, time, and pressure $[24,26]$. In order to limit the surface diffusion as a non-densifying mechanism, a high heating rate of $200^{\circ} \mathrm{C} / \mathrm{m}$ was constantly applied during spark plasma sintering of $\mathrm{SnO}_{2}$ ceramics.

\subsection{Characterization of the sintered ceramics}

After removing the graphite foil layer on the surface of SPSed samples (designated as

SPS-SnO 2 ), the bulk densities of sintered ceramics were determined by the Archimedes method. In order to calculate the relative density, the density value obtained by Archimedes' principle was divided to 6.95 $\mathrm{g} / \mathrm{cm}^{3}\left(\mathrm{SnO}_{2}\right.$ theoretical density). $\mathrm{SnO}_{2}$ ceramics were crushed and ground under $63 \mu \mathrm{m}$. Qualitative phase analysis was performed using XRD (MiniFlex600, Rigaku) with a scan speed of $2 \%$ min at $40 \mathrm{~V}$ and 
15A. Phase determination was carried out by the Rietveld method using Material Analysis Using Diffraction (MAUD) software. The fractured surface (cross-sectional area) of samples was polished by the automatic polishing machine (TegraPol-25, Struers). Then, all polished samples were thermally etched at a temperature of $200^{\circ} \mathrm{C}$ lower than sintering temperature to observe fine microstructure. The microstructure analysis and quantitative elemental analysis carried out using SEM (Supra 50VP, Zeiss). In addition, undoped $\mathrm{SnO}_{2}$ ceramics fabricated by conventional technique (designated as $\mathrm{CS}-\mathrm{SnO}_{2}$ ) and a commercial $\mathrm{SnO}_{2}$ target purchased from a target manufacturer (designated as $\mathrm{CM}-\mathrm{SnO}_{2}$ ) were also characterized by the same techniques.

\section{Results And Discussion}

\subsection{Characterization of the starting $\mathrm{SnO}_{2}$ powder}

XRD pattern and SEM image of starting powder are illustrated in Fig. 1 and Fig. 2. The powder is composed of only Cassiterite ( $\mathrm{SnO}_{2}$; JCPDS \#41-1445), a Rutile type of crystal structure. According to the SEM image of starting powder, the particle size of $\mathrm{SnO}_{2}$ particles is ranging from 100 to $500 \mathrm{~nm}$ with irregular morphologies. The average particle size measured from the SE images is $150 \mathrm{~nm}$. The specific surface area and calculated equivalent spherical diameter of starting powder particle size by the BET method are $7.6 \mathrm{~m}^{2} / \mathrm{g}$ and $110 \mathrm{~nm}$, respectively. The chemical purity of the starting $\mathrm{SnO}_{2}$ powder measured by XRF is shown in Table 1 . The $\mathrm{SnO}_{2}$ powders have high purity and are suitable for the sputtering process without any purification before sintering. The loss on ignition value is neglected due to its shallow value $(<0.1 \%)$.

Table 1

XRF results of pressed $\mathrm{SnO}_{2}$ starting powder

\begin{tabular}{|llll|}
\hline Elements in oxide & $\mathrm{SnO}_{2}$ & $\mathrm{Fe}_{2} \mathrm{O}_{3}$ & Others $\left(\mathrm{Na}_{2} \mathrm{O}, \mathrm{SiO}_{2}, \mathrm{Al}_{2} \mathrm{O}_{3}\right)$ \\
\hline Mass fraction (\%) & 99.950 & 0.025 & 0.025 \\
\hline
\end{tabular}

3.2 Spark plasma sintering of undoped $\mathrm{SnO}_{2}$ 
Table 2

Sintering parameters and properties of $\mathrm{SnO}_{2}$ ceramics sintered by different techniques

\begin{tabular}{|c|c|c|c|c|c|c|}
\hline Sample Code & $\begin{array}{l}\text { Pressure } \\
(\mathrm{MPa})\end{array}$ & $\begin{array}{l}\text { H. Rate } \\
\left({ }^{\circ} \mathrm{C} / \mathrm{min}\right)\end{array}$ & $\begin{array}{l}\text { S. Temp. } \\
\left({ }^{\circ} \mathrm{C}\right)\end{array}$ & $\begin{array}{l}\text { D. Time } \\
\text { (min) }\end{array}$ & $\begin{array}{l}\text { R. Density } \\
(\% \pm 1)\end{array}$ & $\begin{array}{l}\text { Grain Size } \\
\text { (Average in } \mu \mathrm{m} \text { ) }\end{array}$ \\
\hline $\mathrm{SPSO}^{-\mathrm{SnO}_{2}}$ & 30 & 200 & 850 & 10 & 70 & - \\
\hline $\mathrm{SPS1}_{-\mathrm{SnO}_{2}}$ & 30 & 200 & 950 & 1 & 82 & $\sim 0.5$ \\
\hline SPS2-SnO 2 & 30 & 200 & 950 & 3 & 87 & $\sim 0.5$ \\
\hline $\mathrm{SPS}_{3}-\mathrm{SnO}_{2}$ & 30 & 200 & 950 & 5 & 93 & $\sim 0.3$ \\
\hline $\mathrm{SPS}_{4}-\mathrm{SnO}_{2}$ & 30 & 200 & 950 & 10 & 94 & $0.2-0.3$ \\
\hline $\mathrm{SPS}_{-}-\mathrm{SnO}_{2}$ & 30 & 200 & 1050 & 10 & 94 & $\sim 0.5$ \\
\hline $\mathrm{CS}_{1-S n O}$ & 0.1 & 10 & 1200 & 120 & 63 & 0.5 \\
\hline $\mathrm{CS} 2-\mathrm{SnO}_{2}$ & 0.1 & 10 & 1300 & 120 & 63 & 1.0 \\
\hline $\mathrm{CS}_{3}-\mathrm{SnO}_{2}$ & 0.1 & 10 & 1400 & 120 & 63 & 3.0 \\
\hline $\mathrm{CM}-\mathrm{SnO}_{2}$ & N. A. & N. A. & N. A. & N. A. & 63 & $3.0-5.0$ \\
\hline
\end{tabular}

Sintering parameters and properties of sintered ceramics are given in Table 2. For constantly applied pressure, heating rate, sintering temperature $\left(950^{\circ} \mathrm{C}\right)$, with the increment of dwell time from 1 to $10 \mathrm{~min}$, relative density of SPSed $\mathrm{SnO}_{2}$ increased from 82 to $94 \%$. The relative density values of $\mathrm{SPS}_{-}-\mathrm{SnO}_{2}$ and SPS2-SnO ${ }_{2}$ are found below $92 \%$, which signs the limited densification into the second step. The relative density gradually increases from 82 to $93 \%$ with the increment of dwell time from $1 \mathrm{~min}$ to $5 \mathrm{~min}$. When the dwell time increases from $5 \mathrm{~min}$ to $10 \mathrm{~min}$, the relative density increases only $2 \%$ (up to $94 \%$ ), and average grain size reduces unexpectedly. It is consistent with theoretical knowledge that the required sintering time for densification exponentially increases while the relative density reaches maximum point [24]. After increasing sintering temperature from $950^{\circ} \mathrm{C}$ to $1050^{\circ} \mathrm{C}$ with constant dwell time (10 min), relative density remains same ( $94 \%$ ), and average grain size increases. The relative density of conventionally sintered $\mathrm{SnO}_{2}$ is same (63\%), although sintering temperature increases from $1200^{\circ} \mathrm{C}$ to $1400^{\circ} \mathrm{C}$ under constant pressure, heating rate and dwell time. Commercial target has the same relative density as conventionally sintered $\mathrm{SnO}_{2}$.

XRD patterns of sintered ceramics are given in Fig. 3. According to the obtained results, all SPSed ceramics is composed of $\mathrm{SnO}_{2}$ (Cassiterite; JCPDS \#41-1445) as a monolithic crystalline phase except 
the SPS5-SnO 2 sintered at $1050^{\circ} \mathrm{C}$ that contains $\mathrm{SnO}_{2}$ and elemental Tin (Sn; JCPDS \#04-0673). Thus, it confirms that a reasonable amount of elemental $\mathrm{Sn}$ is formed at $1050^{\circ} \mathrm{C}$ and solidifies during cooling.

\subsubsection{Effect of sintering temperature on microstructure development}

$\mathrm{SnO}_{2}(\mathrm{~s}) \Leftrightarrow \mathrm{SnO}(\mathrm{g})+\frac{1}{2} \mathrm{O}_{2}(\mathrm{~g})(1)$

$\mathrm{SnO}_{2}(\mathrm{~s}) \Leftrightarrow \mathrm{Sn}(\mathrm{l})+\mathrm{O}_{2}(\mathrm{~g})(2)$

As stated before, the relative density remains the same even though the sintering temperature is raised from $950^{\circ} \mathrm{C}$ to $1050^{\circ} \mathrm{C}$, and only SPS5-SnO 2 contains elemental Tin (Sn; JCPDS \# 04-0673) as a secondary phase. Rietveld analysis pattern obtained from powder diffraction data of $\mathrm{SPS} 5-\mathrm{SnO}_{2}$ is given in Fig. 4. According to phase determination carried out by the Rietveld method, elemental Tin content in SPS5-SnO 2 is $\sim 3 \mathrm{wt}$ \%. There are two possible chemical reactions for the decomposition of $\mathrm{SnO}_{2}$ which are given in (1) and (2). $\Delta \mathrm{G}$-Temperature diagrams for the decomposition reactions, obtained using FactSage thermochemical software (7.3 version), are illustrated in Fig. 5. Considering the vacuuming status of the SPS chamber, the atmospheric pressure value set $1 \times 10^{-5}$ bar during calculations. $\Delta G$ values of decomposition reactions are negative above $1200^{\circ} \mathrm{C}$ and $1650^{\circ} \mathrm{C}$ under vacuum indicating that $\mathrm{SnO}_{2}$ decomposition can spontaneously proceed above these temperatures in theoretically. The presence of $\mathrm{Sn}$

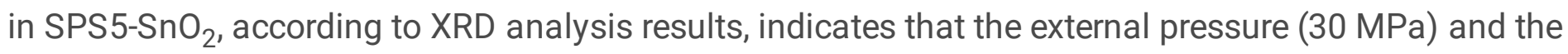
external electric field applied during the SPS process can decrease the total free energy of reaction (2). It should be considered that the external electric field increases ion migration (chemical potential) [26]. Hence, the decomposition reaction was thermodynamically favorable even at $1050^{\circ} \mathrm{C}$ in comparison to $1650^{\circ} \mathrm{C}$, which is expected to occur without any electric field effect. As a result, solid $\mathrm{SnO}_{2}$ was able to decompose into $\mathrm{Sn}(\mathrm{l})$ and $\mathrm{O}_{2}(\mathrm{~g})$. Following to thermal process, the solidified $\mathrm{Sn}$ in the structure could be detected by $\mathrm{XRD}$ as a minor crystalline phase.

SEM images (BSD mode) of SPS4-SnO ${ }_{2}$ and SPS5-SnO ${ }_{2}$ are given in Fig. 6 . It is observed that the grain

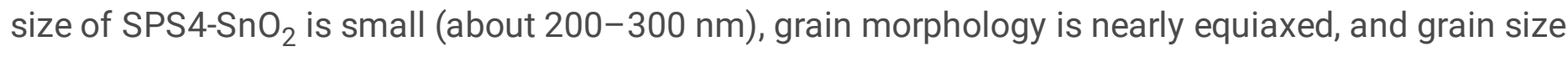
distribution is homogenous. Also, elemental $\mathrm{Sn}$ in trace amount is formed as a decomposition product, which could not be clearly observed by XRD. As seen in Fig. 6(a), Sn particles can be seen on the surface of $\mathrm{SnO}_{2}$, having bright contrast, since decomposition of $\mathrm{SnO}_{2}$ particles starts on grain boundaries. When the sintering temperature of $\mathrm{SnO}_{2}$ is increased further up to $1050^{\circ} \mathrm{C}$, the grain growth is accelerated by means of agglomerated Sn grains distributed non-homogenously. In addition to that, higher content of decomposed elemental Sn can now be easily detected by XRD analysis, preventing achieving full densification due to condensation-evaporation mechanism. Delorme et al. [23] showed similar decomposition behavior of undoped $\mathrm{SnO}_{2}$ at $1050^{\circ} \mathrm{C}$ for 5 min under $37.5 \mathrm{MPa}$ during SPS. 
The temperature and displacement (relative piston travel) curves obtained through spark plasma sintering of SPS4-SnO 2 and SPS5-SnO 2 are demonstrated in Fig. 8. All temperature curves show one stepheating schedule. The displacement curves obtained by the piston motion demonstrate the compaction of the samples during the heating cycle as indicated by the z-axis increment. The displacement values obtained by schedule data, from the beginning of the heating stage at room temperature untill the end of the heating cycle, are $1.79 \mathrm{~mm}$ and $2.02 \mathrm{~mm}$ for SPS4-SnO 2 , and $\mathrm{SPS} 5-\mathrm{SnO}_{2}$, respectively. For these specimens, compaction occurs at an early stage due to applied pressure, expansion is observed above $400^{\circ} \mathrm{C}$ because of the increase of temperature, and a high shrinkage takes place above $800^{\circ} \mathrm{C}$ until the end of dwell time given at top temperature. It means that the densification starts at $\sim 800^{\circ} \mathrm{C}$ and makes a huge contribution to shrinkage (displacement). During the sintering of $\mathrm{SPS} 4-\mathrm{SnO}_{2}$, the displacement rate (ratio of displacement to temperature) slows down at $950^{\circ} \mathrm{C}$ after 3 min due to densification. However, the rising temperature or the increasing displacement does not always refer to a higher densification rate. Even though SPS5-SnO ${ }_{2}$ is sintered at a higher temperature $\left(1050^{\circ} \mathrm{C}\right)$ and displacement curves indicate maximum displacement value at $2.02 \mathrm{~mm}$, the relative density values of $\mathrm{SPS}_{-}-\mathrm{SnO}_{2}$ and $\mathrm{SPS} 5-\mathrm{SnO}_{2}$ are equal. In this situation, the increase of temperature leads to the formation of elemental $\mathrm{Sn}$ in a high amount. A rapid displacement at $1050^{\circ} \mathrm{C}$ points out the ejection of $\mathrm{Sn}$ from the graphite mold. Considering the higher theoretical density of $\mathrm{Sn}\left(\sim 7.265 \mathrm{~g} / \mathrm{cm}^{3}\right)$ than that of $\mathrm{SnO}_{2}\left(\sim 6.9 \mathrm{~g} / \mathrm{cm}^{3}\right)$ and a relatively higher content of $\mathrm{Sn}$ in $\mathrm{SPS} 5-\mathrm{SnO}_{2}$, the same relative density of $\mathrm{SPS} 4-\mathrm{SnO}_{2}$ and $\mathrm{SPS} 5-\mathrm{SnO}_{2}$ indicates less densification of SPS5-SnO ${ }_{2}$ in which $\mathrm{Sn}$ exists as a secondary phase.

As known, diffusion is the most crucial sintering mechanism. According to Arrhenius' expression,

the diffusion is temperature-dependent. Hence, the increasing sintering temperature increases the sintering rate by promoting atomic diffusion $(24,27)$. For this reason, the effect of sintering temperature on microstructural development of SPSed ceramics has been investigated in this section. However, relative density is limited to $94 \%$ even if sintering temperature is raised from $950^{\circ} \mathrm{C}$ to $1050^{\circ} \mathrm{C}$. Full densification could not be provided owing to elemental $\mathrm{Sn}$ as a secondary phase formed through the decomposition of $\mathrm{SnO}_{2}$, which is consistent with the literature [21].

\subsubsection{Effect of dwell time on microstructure development}

The obtained results from previous SPS experiments show that $950^{\circ} \mathrm{C}$ is the optimal sintering temperature because higher sintering temperature leads to the formation of secondary phase. Still, SPS4$\mathrm{SnO}_{2}$ contains a trace amount of elemental $\mathrm{Sn}$ in its microstructure. To investigate the effect of dwell time on densification, phase evolution, and microstructural development, the different dwell times $(1,3,5$, $10 \mathrm{~min})$ were applied at an optimal sintering temperature $\left(950^{\circ} \mathrm{C}\right)$ during spark plasma sintering. As stated before, the relative density of ceramics SPSed at $950^{\circ} \mathrm{C}$ increases from 82 to $94 \%$ with the increment of dwell time from $1 \mathrm{~min}$ to $10 \mathrm{~min}$. According to XRD patterns, they consist of only $\mathrm{SnO}_{2}$ phase.

SEM images (BSD mode) of SPS1-SnO $2, \mathrm{SPS}_{2}-\mathrm{SnO}_{2}, \mathrm{SPS}_{-}-\mathrm{SnO}_{2}$ and $\mathrm{SPS}_{-}-\mathrm{SnO}_{2}$ are given in Fig. 9. 
It is seen that the grain size of SPS1-SnO ${ }_{2}$ and $\mathrm{SPS} 2-\mathrm{SnO}_{2}$ is unexpectedly larger than that of both SPS3$\mathrm{SnO}_{2}$ and SPS4-SnO 2 . The agglomerated grains in the microstructure of $\mathrm{SPS} 1-\mathrm{SnO}_{2}$ and $\mathrm{SPS}_{2}-\mathrm{SnO}_{2}$ are illustrated with red plus signs (+) in Fig. 9. Non-homogenous grain size distribution is associated with the presence of agglomerates with a size above $500 \mathrm{~nm}$. However, there is no significant grain growth for SPS3-S $\mathrm{SnO}_{2}$. A further increase in dwell time up to 10 min develops a microstructure containing grains with smaller average size. Although a holding time of more than $10 \mathrm{~min}$ is needed to eliminate isolated pores (complete densification), the maximum dwell time is selected as 10 min to prevent further decomposition of $\mathrm{SnO}_{2}$ and limit liquid $\mathrm{Sn}$ content. The grain size reduction above $5 \mathrm{~min}$ is associated with the starting of decomposition of $\mathrm{SnO}_{2}$ into $\mathrm{Sn}$ on grain boundaries, where grain growth of $\mathrm{SnO}_{2}$ is suppressed without affecting the densification mechanism. A slight decrease in grain size $(\sim 50 \mathrm{~nm})$ might be attributed to decreasing volume of reduced $\mathrm{SnO}_{2}$ into $\mathrm{Sn}$ at the beginning of decomposition phenomena. In addition, the particle size of starting powder is $100-200 \mathrm{~nm}$, and the average grain size of SPS4-SnO ${ }_{2}$ is found about $200-300 \mathrm{~nm}$. It shows that grain growth is minimal due to different sintering mechanisms of SPS where the pulse current flows through powder particles and then the heating power is dissipating at the contact points of particles [18].

The temperature and displacement curves of SPS1-SnO ${ }_{2}, \mathrm{SPS} 3-\mathrm{SnO}_{2}$ and $\mathrm{SPS}_{-}-\mathrm{SnO}_{2}$ are demonstrated in

Figure 10. The process data of SPS2-SnO 2 could not be collected because of a technical problem. The shrinkage rate remarkably increases above $800^{\circ} \mathrm{C}$ during the one step-heating cycles. The total displacement value is found $1.54 \mathrm{~mm}, 1.71 \mathrm{~mm}$, and $1.79 \mathrm{~mm}$ for $\mathrm{SPS}_{-}-\mathrm{SnO}_{2}, \mathrm{SPS}_{-}-\mathrm{SnO}_{2}$ and SPS4$\mathrm{SnO}_{2}$, respectively. The displacement (density) non-proportionally increases with the gradual increase in dwell time. As seen in Fig. 10(b) and Fig. 10(c), the full compaction cannot be provided in 5 min because displacement ratio is high, while the displacement reaches a plateau after 5 min where the shrinkage rate is too low. On the other hand, a plateau on displacement curve refers to higher densification for SPS4$\mathrm{SnO}_{2}$, whereas that contains elemental $\mathrm{Sn}$ in trace amount. In order to produce monolithic $\mathrm{SnO}_{2}$ ceramics with high chemical purity, $5 \mathrm{~min}$ is selected as the optimal sintering time for SPS.

Figure11 The schematic illustration of microstructural development of SPSed $\mathrm{SnO}_{2}$ ceramics as a function of time and temperature

The schematic illustration of microstructural development of SPSed $\mathrm{SnO}_{2}$ ceramics as a function of time and temperature is given in Fig. 11. To summarize the given knowledge in Sect. 3.2., both increment of dwell time from 5 to $10 \mathrm{~min}$ at $950^{\circ} \mathrm{C}$ and the increasing of sintering temperature from $950^{\circ} \mathrm{C}$ to $1050^{\circ} \mathrm{C}$ does not contribute to densification of $\mathrm{SnO}_{2}$ (relative density remains almost the same) because of the evaporation of $\mathrm{SnO}_{2}$ into elemental $\mathrm{Sn}$ followed by condensation of $\mathrm{Sn}$ onto $\mathrm{SnO}_{2}$ grain boundaries that is thermodynamically favorable at $950^{\circ} \mathrm{C}$ under SPS conditions. The formation of $\mathrm{Sn}$ has been firstly seen on grain boundaries on the 10 th min of sintering at $950^{\circ} \mathrm{C}$. Although dwell time is increased from 5 to $10 \mathrm{~min}$, a slight decrease in average grain size is observed unexpectedly, which might be attributed to 
decreasing volume of reduced $\mathrm{SnO}_{2}$ into $\mathrm{Sn}$ at the first moment of decomposition phenomena took place on particle surface under external pressure $(30 \mathrm{MPa})$ and the external electric field. When the sintering temperature rises from $950^{\circ} \mathrm{C}$ to $1050^{\circ} \mathrm{C}$, much more elemental $\mathrm{Sn}$ is formed, and liquid $\mathrm{Sn}$ phase is migrated through $\mathrm{Sn}$ grains by viscous flow under external pressure. Next, liquid $\mathrm{Sn}$ grains are solidified in agglomerated form (Fig. 11) under a high cooling rate $\left(\sim 600^{\circ} \mathrm{C} / \mathrm{min}\right)$ and high vacuum $\left(1 \times 10^{-5} \mathrm{bar}\right)$. Also, average grain size of $\mathrm{SnO}_{2}$ is increased expectedly with the increment of temperature from $950^{\circ} \mathrm{C}$ to $1050^{\circ} \mathrm{C}$ that refers to grain growth governed by surface diffusion, where the size of isolated pores is not decreased through grain boundary and/or lattice diffusion that keeps densification rate constant [24].

\subsection{Comparison of the sintering techniques}

The relative density of $\mathrm{SnO}_{2}$ ceramics remains constant at $63 \%$, although the sintering temperature increases from $1200^{\circ} \mathrm{C}$ to $1400^{\circ} \mathrm{C}$ during conventional sintering. SEM images of conventionally sintered $\mathrm{SnO}_{2}$ ceramics are given in Fig. 12. It can be seen that the increasing sintering temperature causes a remarkable enhancement in grain size. The formation of elemental $\mathrm{Sn}$ from $\mathrm{SnO}_{2}$ decomposition could not be observed.

The average size of equiaxed grains is found roughly $500 \mathrm{~nm}, 1 \mu \mathrm{m}$, and $3 \mu \mathrm{m}$ for $\mathrm{CS}_{1}-\mathrm{SnO}_{2}, \mathrm{CS} 2-\mathrm{SnO}_{2}$, and $\mathrm{CS} 3-\mathrm{SnO}_{2}$, respectively. Without any improvement in densification, the grain growth points out the surface diffusion occurred as a dominant mass transportation mechanism [24]. Therefore, $1200^{\circ} \mathrm{C}$ is chosen as an optimal sintering temperature for conventional sintering to prepare the sputtering target.

There is a significant difference in relative density values of $\mathrm{SPS} 3-\mathrm{SnO}_{2}$ and $\mathrm{CS}^{-} \mathrm{SnO}_{2}$. The low relative density (63\%) indicates that the second step of sintering cannot be reached even at $1200^{\circ} \mathrm{C}$ for $120 \mathrm{~min}$. The reason is related to not only lattice and grain boundary diffusion, but also plastic deformation and creep that took place during pressure-assisted sintering $[24,26]$. A higher density is achieved under using SPS at a lower temperature in reduced time because the densification rate relative to the coarsening rate increases by pulsed current (typically a few thousand amperes) under a pulsed DC voltage and external pressure as a capillary pressure. They promote mass transport by enhancing the total interfacial energy of curvature under deformation $[18,24]$.

$\mathrm{CM}-\mathrm{SnO}_{2}$ has the same density value compared to $\mathrm{CS}-\mathrm{SnO}_{2}$ ceramics. It means that the commercial product was produced by a conventional (pressureless) technique.

XRD patterns given in Fig. 13 show that $\mathrm{SPS} 3-\mathrm{SnO}_{2}, \mathrm{CS} 1-\mathrm{SnO}_{2}$, and $\mathrm{CM}-\mathrm{SnO}_{2}$ are composed of only $\mathrm{SnO}_{2}$ phase. Figure 14 illustrates the SEM images (SE mode) of $\mathrm{SPS}_{-}-\mathrm{SnO}_{2}, \mathrm{CS} 1-\mathrm{SnO}_{2}$ and $\mathrm{CM}-\mathrm{SnO}_{2}$. The effect of the sintering technique on the microstructure of ceramics can be easily noticed. SPSed $\mathrm{SnO}_{2}$ has a partially dense microstructure containing fine $\mathrm{SnO}_{2}$ grains with an average size of $\sim 300 \mathrm{~nm}$. Conventionally sintered $\mathrm{SnO}_{2}$ has not a dense microstructure. Neck formation occurs without grain growth and pore isolation. $\mathrm{SnO}_{2}$ grains in equiaxed shape have an average size of $500-600 \mathrm{~nm}$. Like $\mathrm{CS} 1-\mathrm{SnO}_{2}, \mathrm{CM}_{-}-\mathrm{SnO}_{2}$ possesses the same density and a non-dense microstructure where the sintering is 
limited with neck formation. However, the grain size is larger than $3 \mu \mathrm{m}$, and the grains are distributed inhomogeneously. That could be caused by a coarser starting powder of $\mathrm{CM}^{-\mathrm{SnO}_{2}}$ compared to CS1$\mathrm{SnO}_{2}$.

\section{Conclusions}

In the present study, $\mathrm{SnO}_{2}$ ceramics were produced from undoped submicron $\mathrm{SnO}_{2}$ powders using the SPS and pressureless-assisted sintering techniques by optimizing sintering conditions. The pressureless sintered $\mathrm{SnO}_{2}$ ceramics at $1200^{\circ} \mathrm{C}-1400^{\circ} \mathrm{C}$ for 120 min exhibit very poor densification behavior and hence relatively low relative density (i.e., $63 \%$ relative density) due to the dominance of non-densifying evaporation-condensation mechanism. On the other hand, monolithic $\mathrm{SnO}_{2}$ ceramics were successfully produced by SPS at $950^{\circ} \mathrm{C}$ for $5 \mathrm{~min}$, which demonstrated $93 \%$ relative density and homogeneous grain size distribution. These results show that the pressure assistance in SPS dominates the densifying mechanisms against to non-densifying mechanisms. In addition, they reveal the effect of process conditions and sintering technique (sintering mechanism) on densification behavior, phase evolution, and microstructural development of $\mathrm{SnO}_{2}$ ceramics. Accordingly, SPSed $\mathrm{SnO}_{2}$ ceramics can be used as sputtering targets to produce high quality gas sensors due to their relatively high density ( $93 \%$ relative density), high chemical purity, homogeneous grain size distribution and smaller average grain size.

\section{Declarations}

\section{Acknowledgments}

This research did not receive any specific grant from funding agencies in the public, commercial, or notfor-profit sectors.

\section{References}

1. Advani GN, Jordan $\mathrm{AG}$, Thin film of $\mathrm{SnO}_{2}$ as a solid state gas sensors. J. Electron. Mater. 1980, $929-$ 49

2. Pianaro SA, Bueno PR, Longo E et al (1995) A new SnO2-based varistor system. J Mater Sci Lett 14:692-694

3. Jiang L, Sun G, Zhou Z et al (2005) Size Controllable Synthesis of Monodispersed SnO2 Nanoparticles and Application in Electrocatalysts. Phys Chem B 109:8774-8778

4. Li F, Chen L, Knowles G et al (2017) Hierarchical Mesoporous SnO2 Nanosheets on Carbon Cloth: A Robust and Flexible Electrocatalyst for $\mathrm{CO} 2$ Reduction with High Efficiency and Selectivity. Angew Chem 56:505-509

5. Dattoli EN, Wan Q, Guo W et al (2007) Fully transparent thin-film transistor devices based on SnO2 nanowires. Nano Lett 7:2463-2469 
6. Aoki A, Sasakura H (1970) Tin oxide thin film transistors. Jpn J Appl Phys 9:582

7. Moulson AJ, Herbert JM (2003) Electroceramics materials properties applications. John Wiley \& Sons Inc, Chichester

8. Shaalan NM, Yamazaki T, Kikuta T (2011) Influence of morphology and structure geometry on NO2 gas-sensing characteristics of $\mathrm{SnO} 2$ nanostructures synthesized via a thermal evaporation method. Sens Actuators B 153:11-16

9. Khuspe GD, Sakhare RD, Navale ST et al (2013) Nanostructured SnO2 thin films for NO2 gas sensing applications. Ceram Int 39:8673-8679

10. Baik N, Sakai G, Miuro N et al (2000) Preparation of stabilized nanosized tin oxide particles by hydrothermal treatment. J AmCeram Soc 83:2983-2987

11. Aciksari C, Tuncolu IG, Suvaci E et al (2016) The Role of Cation Concentration on Particle Formation Mechanism during Hydrothermal Synthesis of Nanosized Tin Oxide (SnO2). J Aust Ceram Soc 52:60-71

12. Falk G. Sintering of Transparent Conductive Oxides: From Oxide Ceramic Powders to Advanced Optoelectronic Materials. Sintering of Ceramics - New Emerging Techniques. Lakshmanan A. Ed. London: InTech, 2012

13. Medvedovski E, Alvarez N, Yankov 0 et al (2008) Advanced indium-tin oxide ceramics for sputtering targets. Ceram Int 34:1173-1182

14. ï»¿ ¿Medvedovski E (2017) Tin oxide-based ceramics of high density obtained by pressureless sintering. Ceram Int 43:8396-8405

15. Hoenig CL, Searcy AW (1996) Knudsen and Langmuir Evaporation Studies of Stannic Oxide. J AmCeram Soc 49:128-134

16. ï» $i$ Leite ER, Cerri JA, Longo E et al (2001) Paskocima, Sintering of ultra fine undoped SnO2 powder. J Eur Ceram Soc 21:669-675

17. Quach DV, Groza JR, Zavaliangos A et al. Fundamentals and applications of field/current assisted sinterin. Sintering of Advanced Materials - Fundamentals and Processes. Fang ZZ. Ed. Cambridge: Woodhead Publishing, 2010

18. Suarez M, Fernandez A, Menendez JL et al. Challenges and opportunities for spark plasma sintering: a key technology for a new generation of materials. Sintering Applications. Ertug B. Ed. London: IntechOpen, 2013

19. Kessel HU, Hennicke J, Schmidt J et al. "FAST" field assisted sintering technology- a new process for the production of metallic and ceramic sintering materials (Engl. Transl.). In: Pulvermetallurgie in Wissenschaft und Praxis Band 22 - Pulvermetallurgie - Kompetenz und Perspektive. Kolaska H. Ed. Conference Proceedings - Hagener Symposium Pulvermetallurgie, 2006

20. Yoshinaka M, Hirota K, Ito M et al (1999) Hot Isostatic Pressing of Reactive SnO2 Powder. J AmCeram Soc 82:216-218 
21. Park JW, Jo W, Kim DY (2005) Enhanced densification of pure SnO2 by spark plasma sintering. Journal of Materials Science 40:3825-3827

22. Rembeza SI, Kosheleva NN, Rembeza ES et al (2014) Synthesis of Compositionally Different Multicomponent Metal-Oxide Films (SnO2)x(ZnO)1-x $(x=1-0.5)$. Semiconductors 48(8):11181122

23. Delorme F, Dujardin R, Schoenstein F et al (2019) Nanostructuring of dense SnO2 ceramics by Spark Plasma Sintering. Ceram Int 45:8313-8318

24. Kang SJL (2005) Sintering: Densification, Grain Growth and Microstructure. Elsevier ButterworthHeinemann, Massachusetts

25. German RM (1996) Sintering theory and practice. John Wiley \& Sons, New York

26. Rahaman MN (2003) Ceramic Processing and Sintering. Marcel Dekker Inc., New York

27. Mitchell BS (2004) An Introduction to Materials Engineering and Science for Chemical and Materials Engineers. John Wiley \& Sons Inc., New Jersey

\section{Figures}




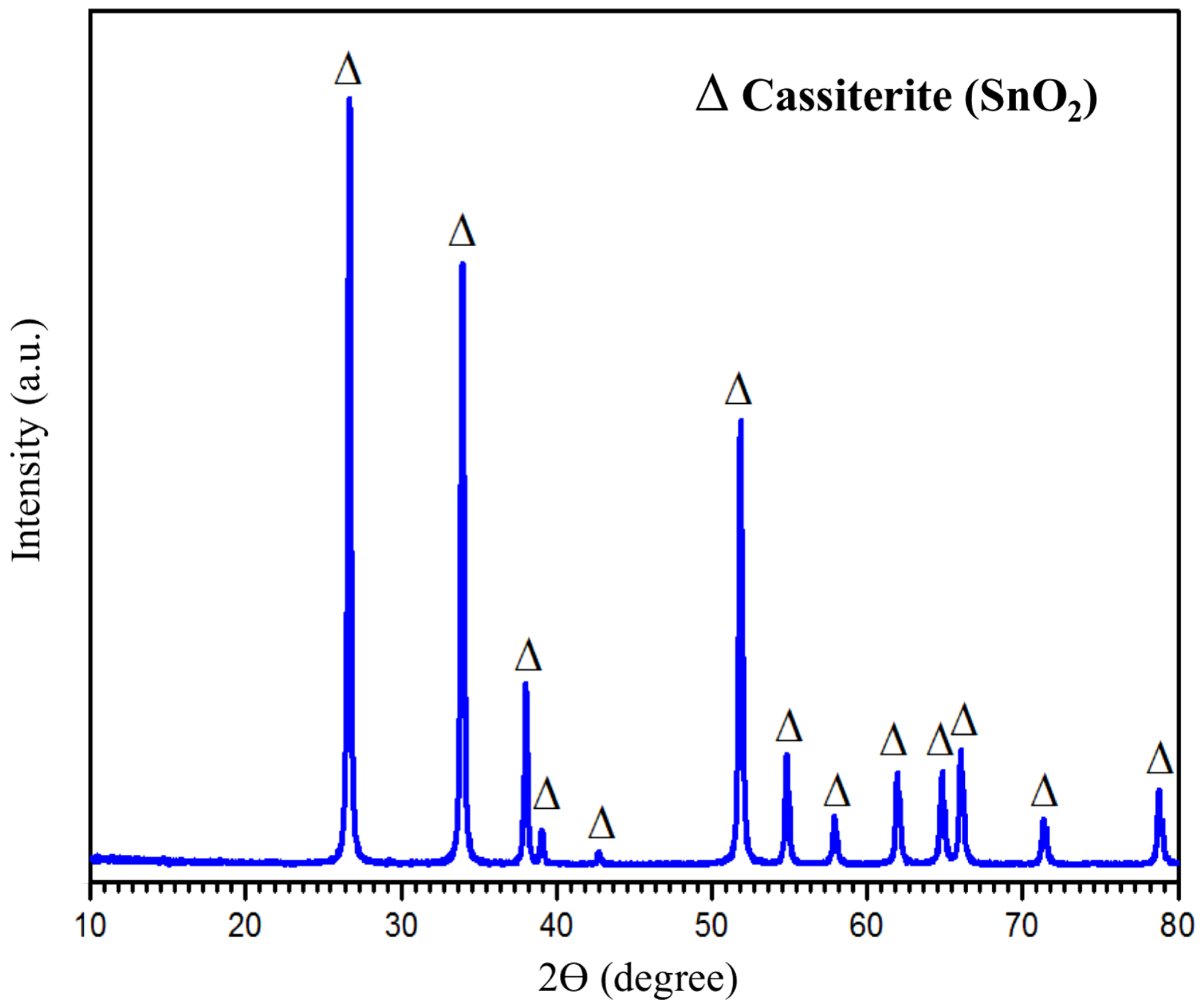

Figure 1

XRD pattern of starting powder 


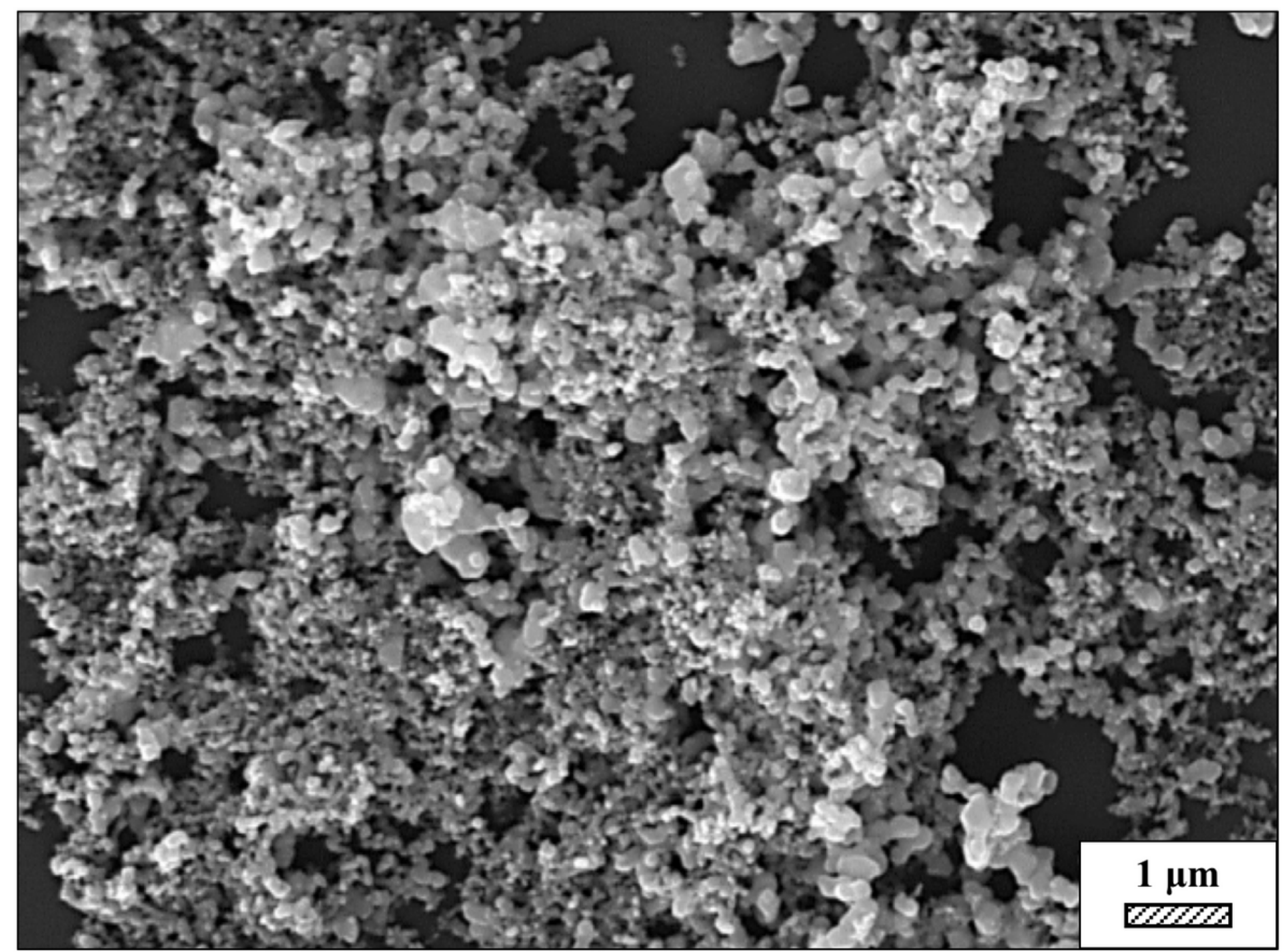

Figure 2

SEM image of starting powder 


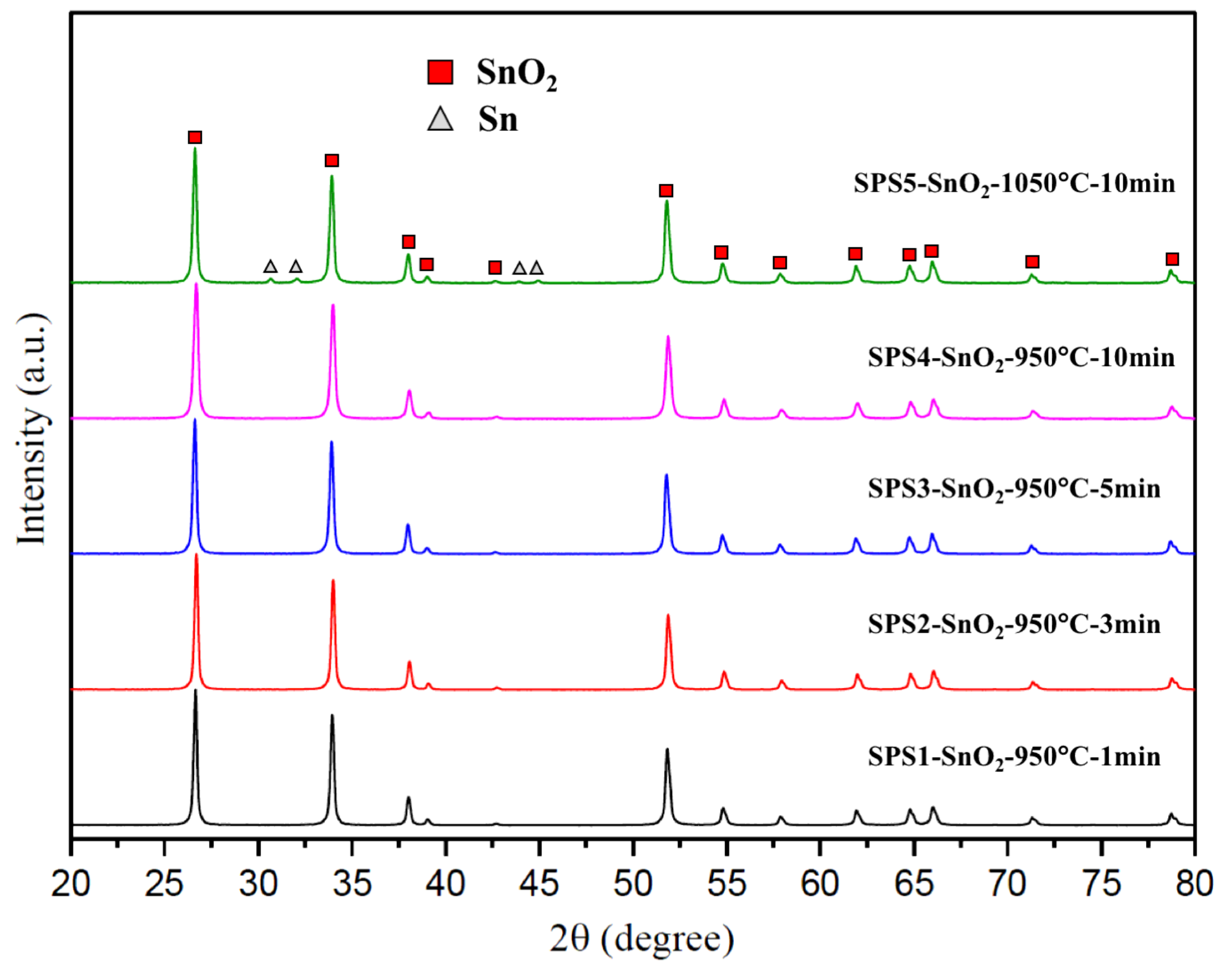

Figure 3

XRD patterns of SPS1-SnO2, SPS2-SnO2, SPS3-SnO2, SPS4-SnO2 and SPS5-SnO2 


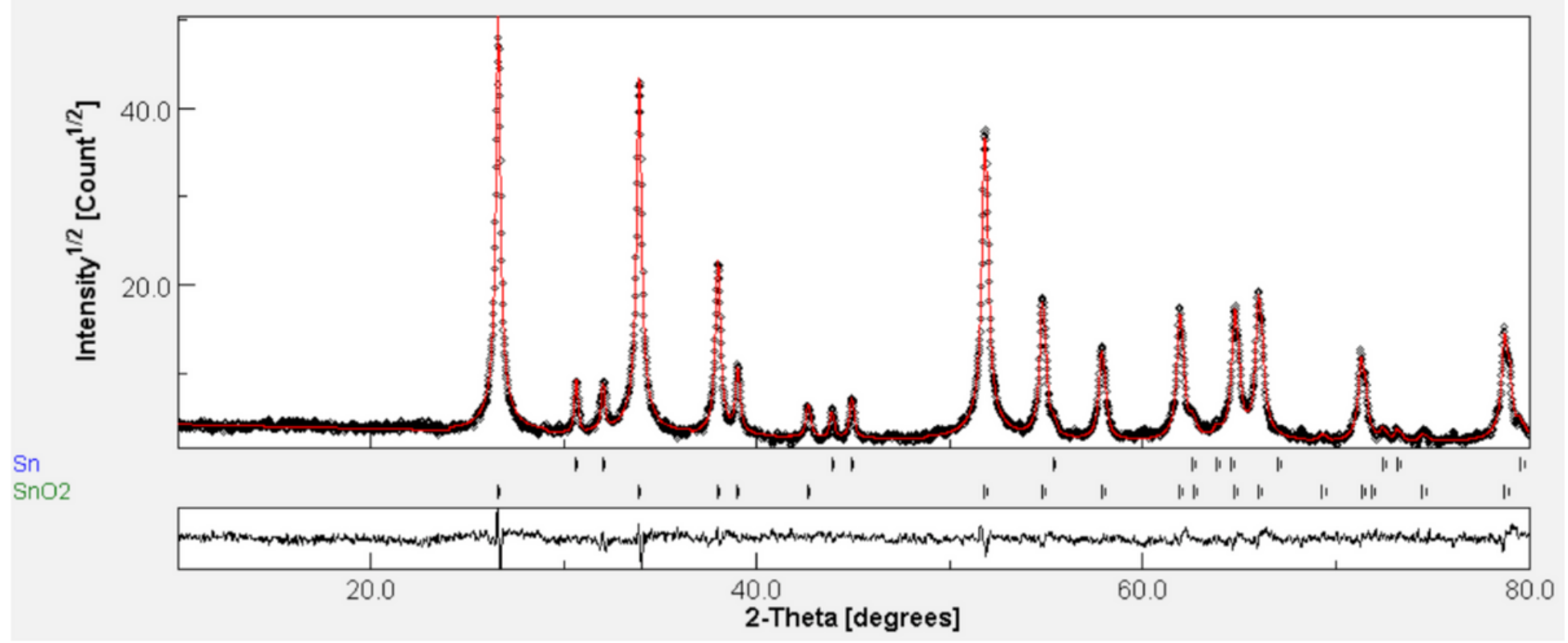

Figure 4

Rietveld analysis pattern obtained from powder diffraction data of SPS5-SnO2. The solid red lines are calculated intensities, and the black marked ones are observed intensities. The difference between the observed and calculated intensities is plotted below the profile. 


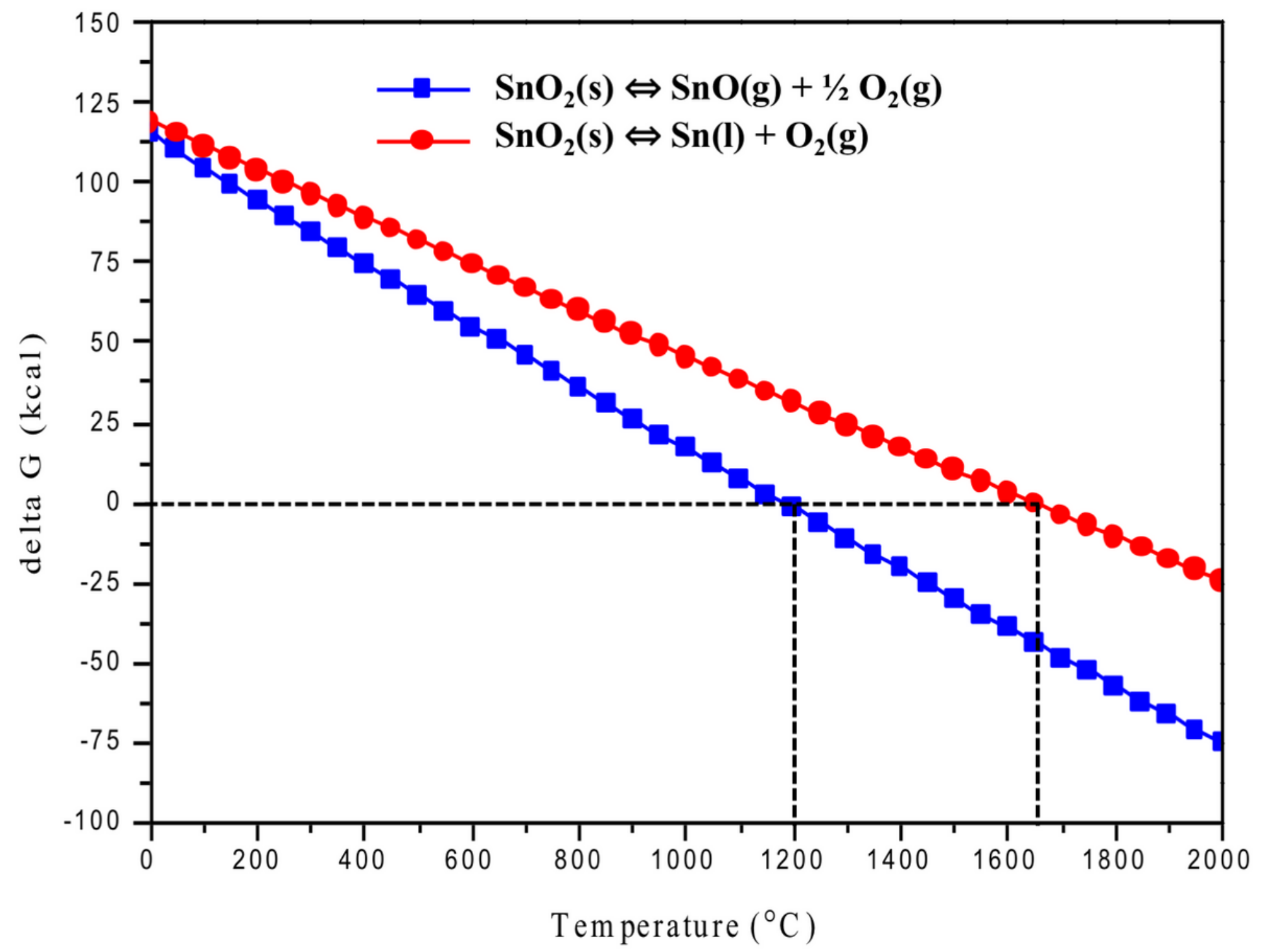

Figure 5

$\Delta \mathrm{G}$-Temperature diagrams for the decomposition reactions of $\mathrm{SnO} 2$
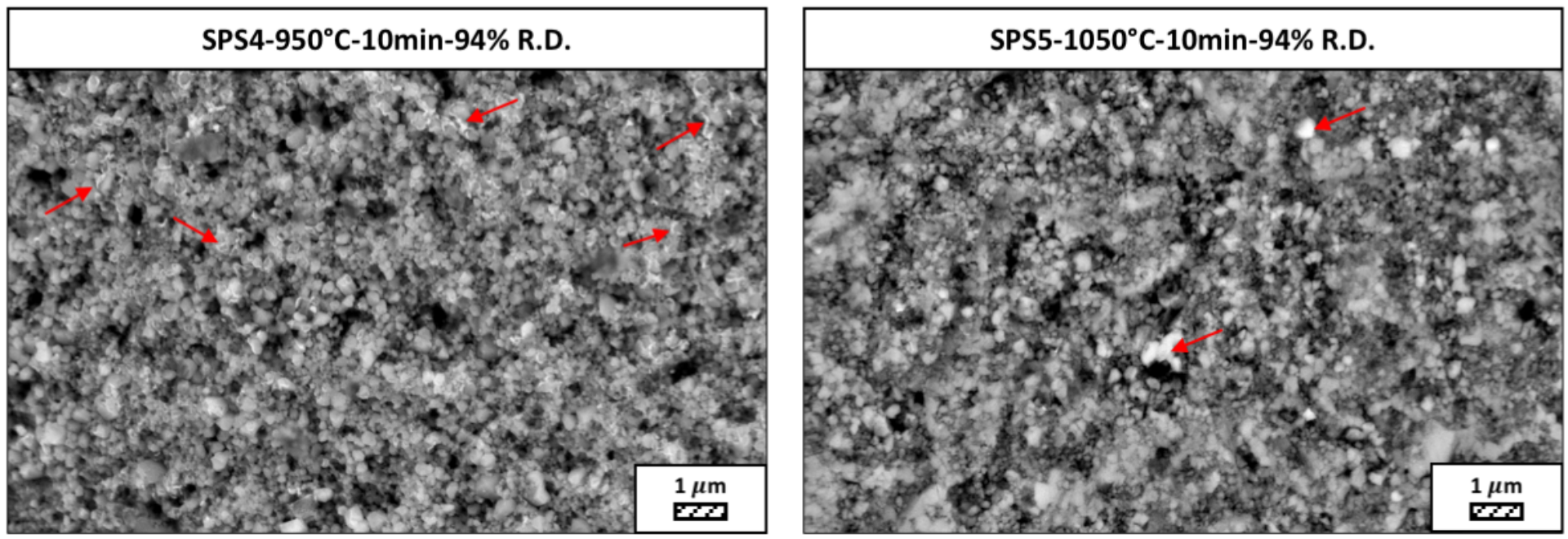

Figure 6 
SEM images (BSD mode) of SPS4-SnO2 and SPS5-SnO2 at equal magnification (20.000x)

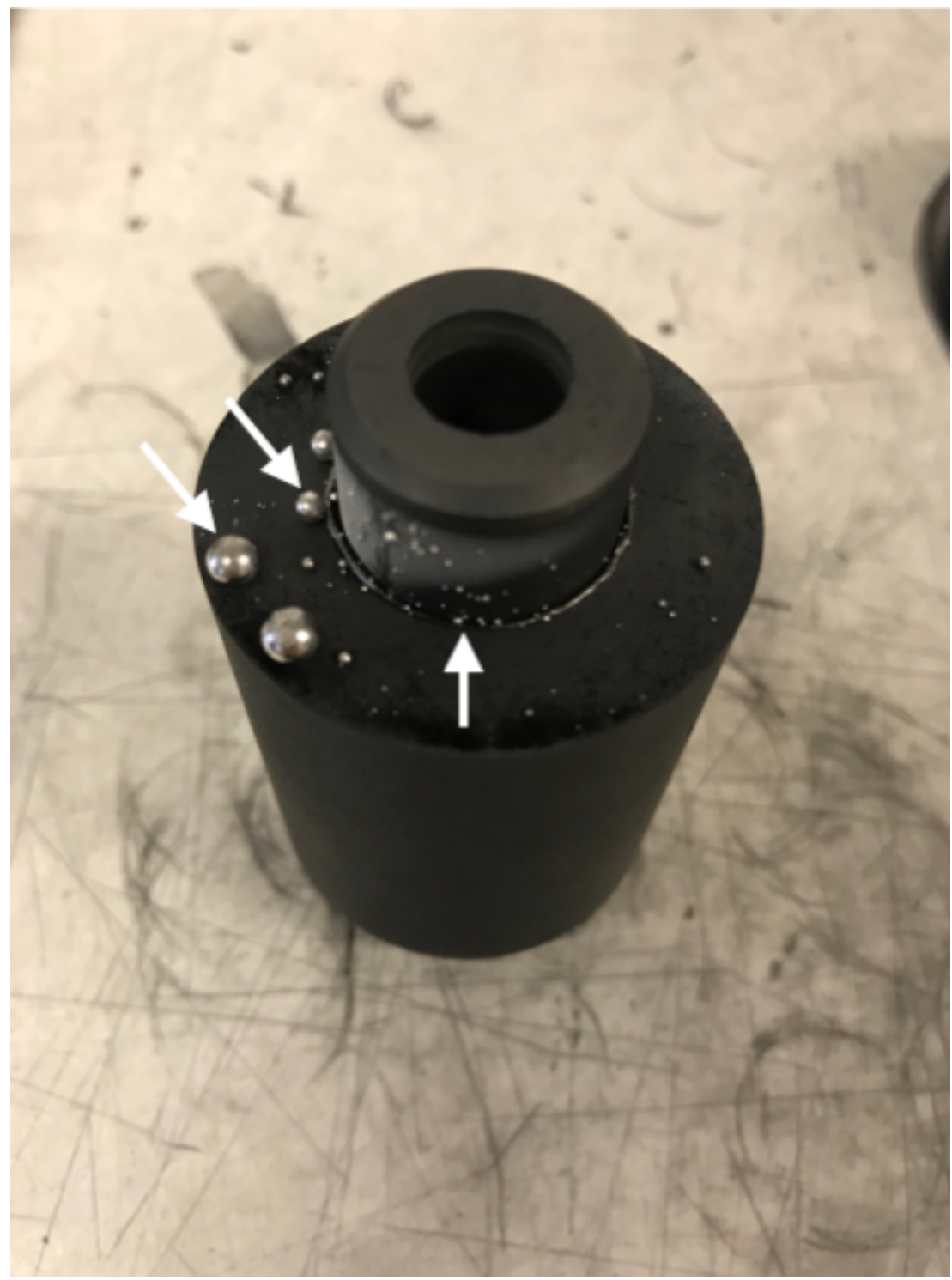

Figure 7

Image of Sn ejected from graphite mold during the sintering of SPS5-SnO2
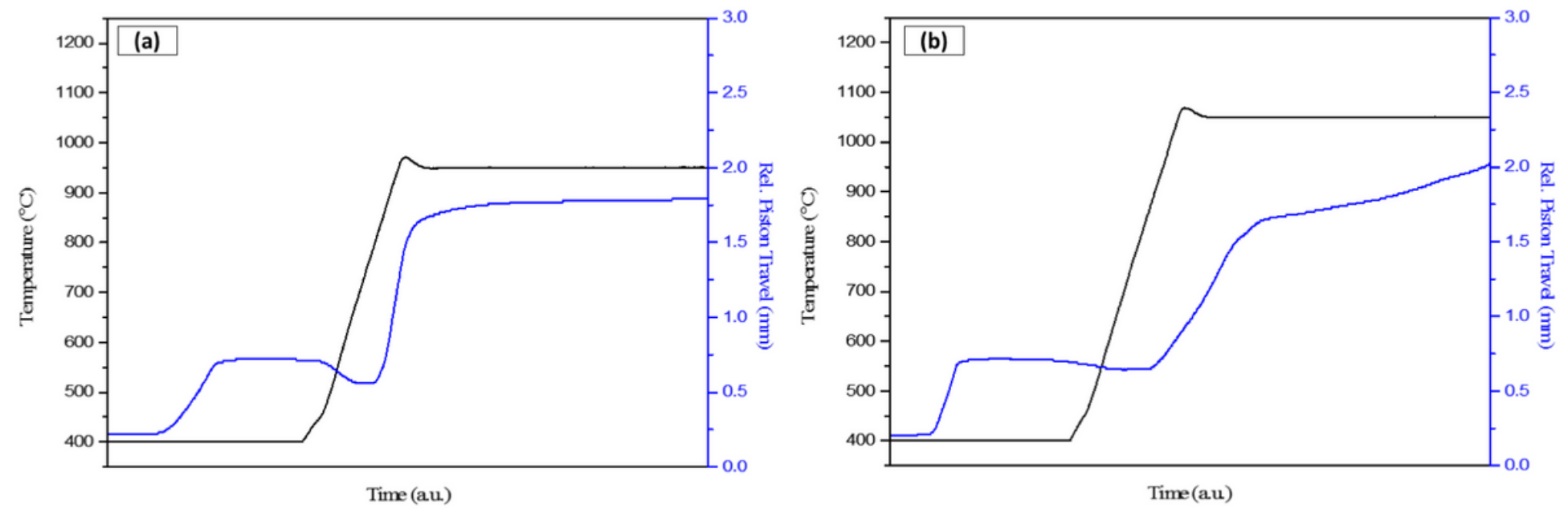

Figure 8 
The temperature and displacement curves obtained through spark plasma sintering of a) SPS4-SnO2 and b) SPS5-SnO2
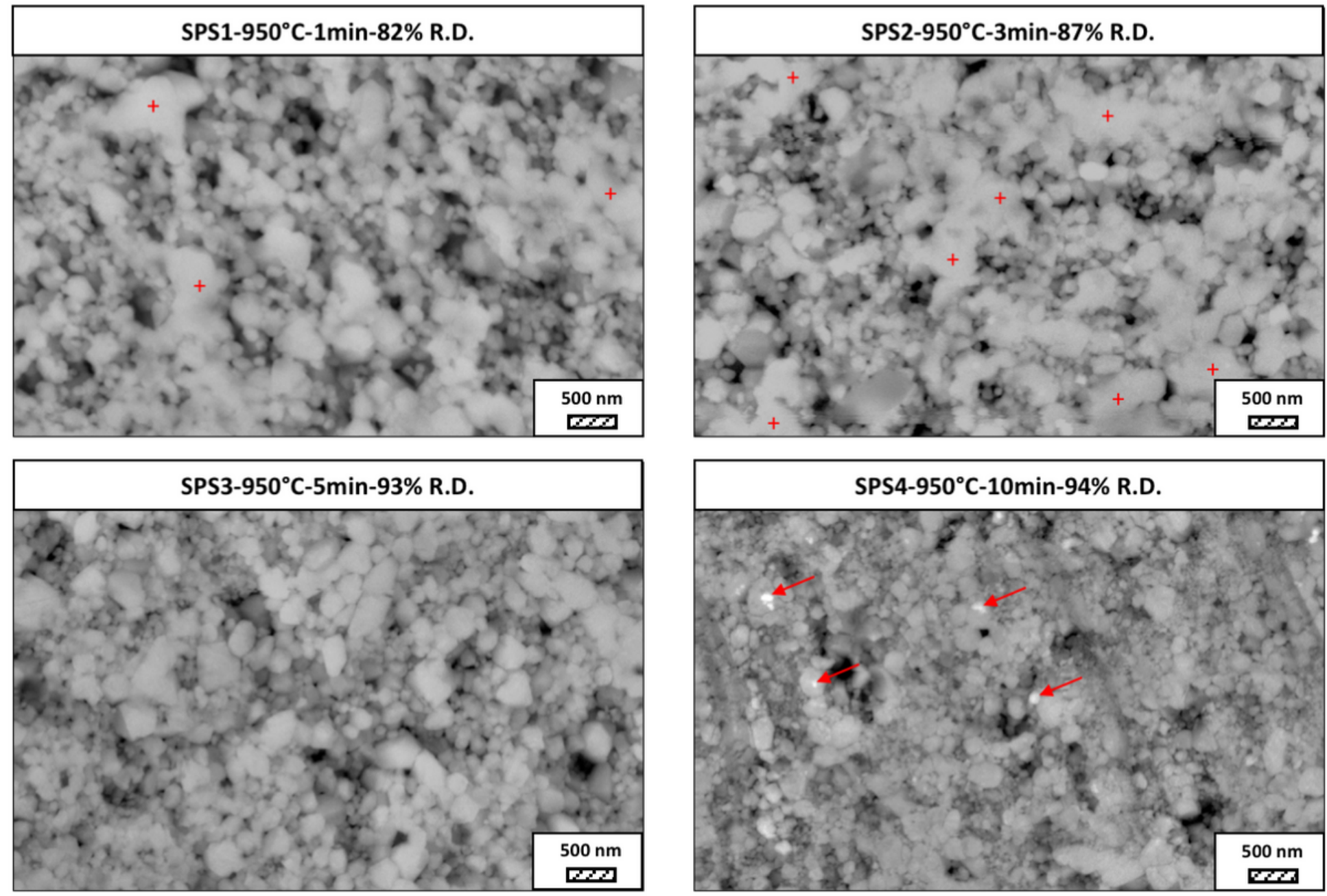

Figure 9

SEM images (BSD mode) of SPS1-SnO2, SPS2-SnO2, SPS3-SnO2 and SPS4-SnO2 at equal magnification $(60.000 x)$ 


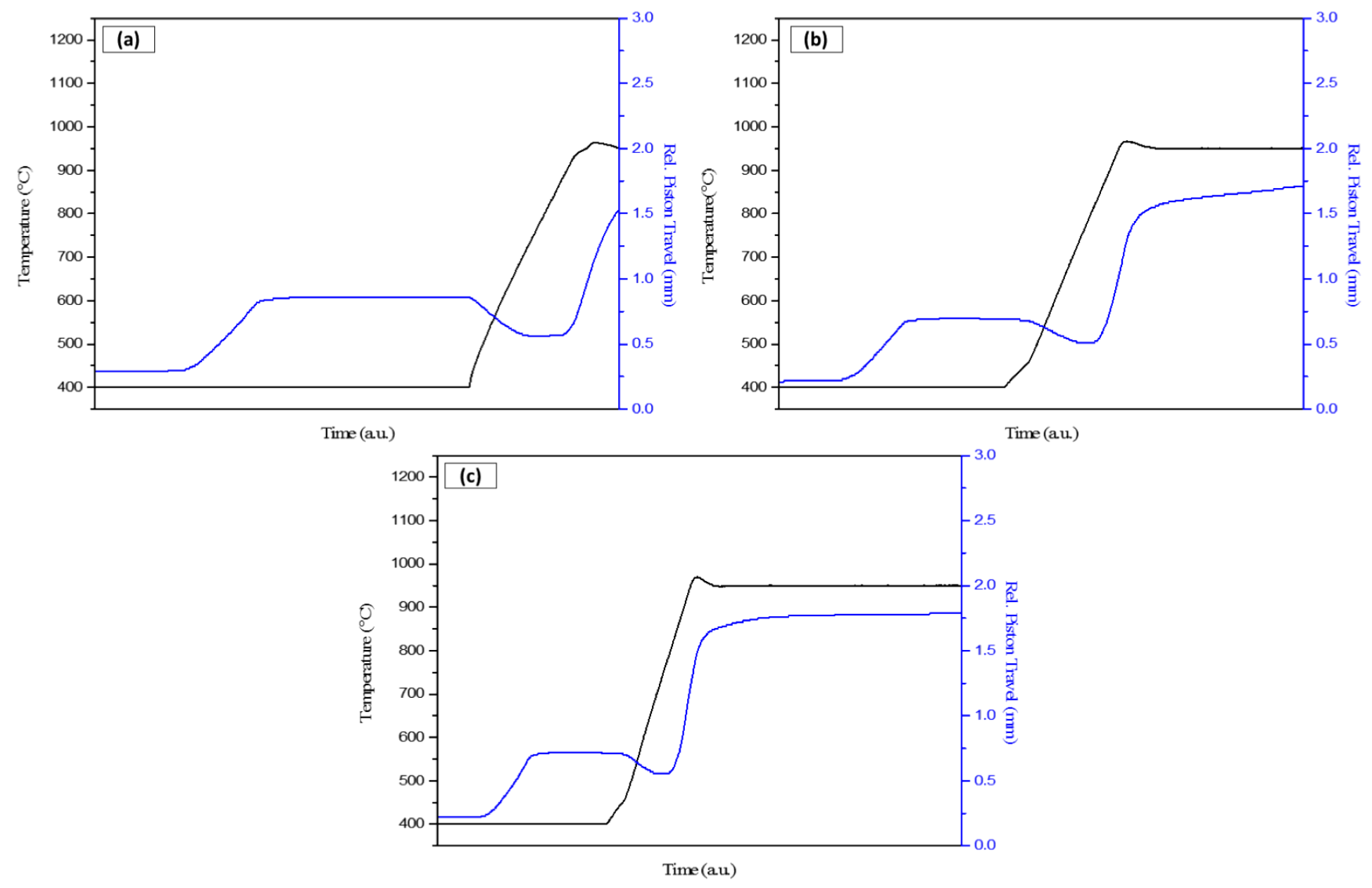

Figure 10

The temperature and displacement curves obtained through spark plasma sintering of a) SPS1-SnO2, b) SPS3-SnO2 and c) SPS4-SnO2 

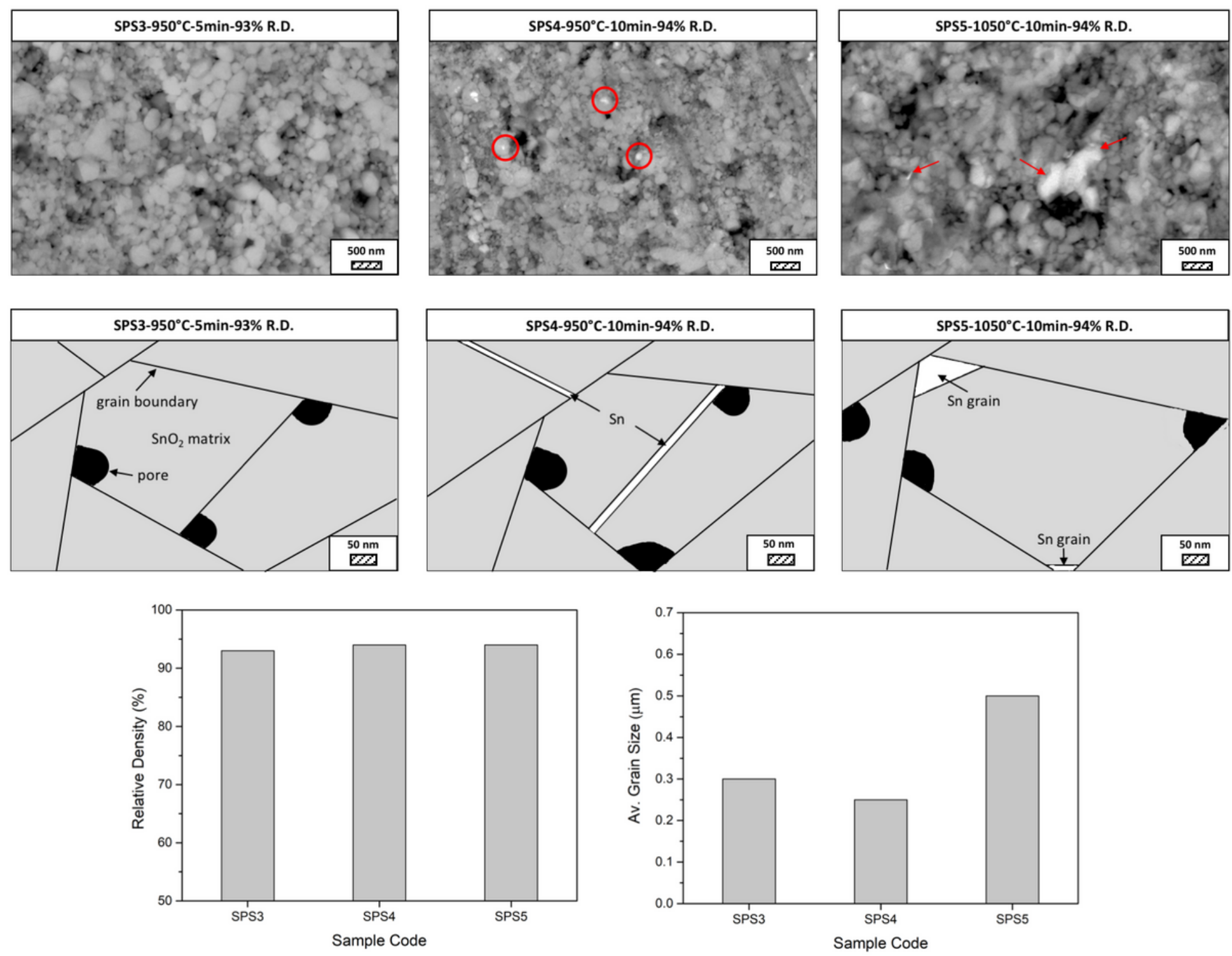

\section{Figure 11}

The schematic illustration of microstructural development of SPSed SnO2 ceramics as a function of time and temperature 

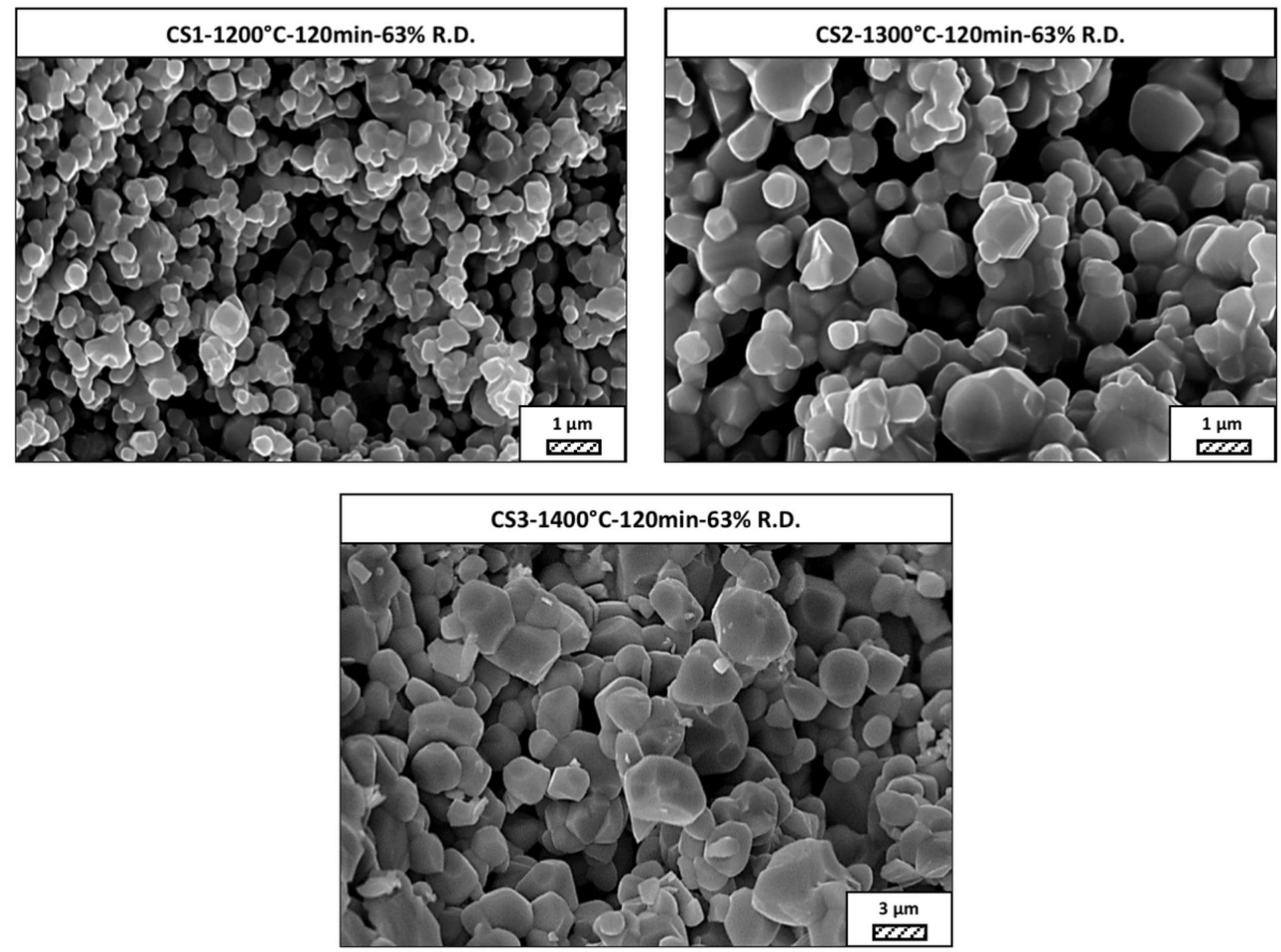

Figure 12

SEM images (SE mode) of conventionally sintered SnO2 ceramics at different temperatures 


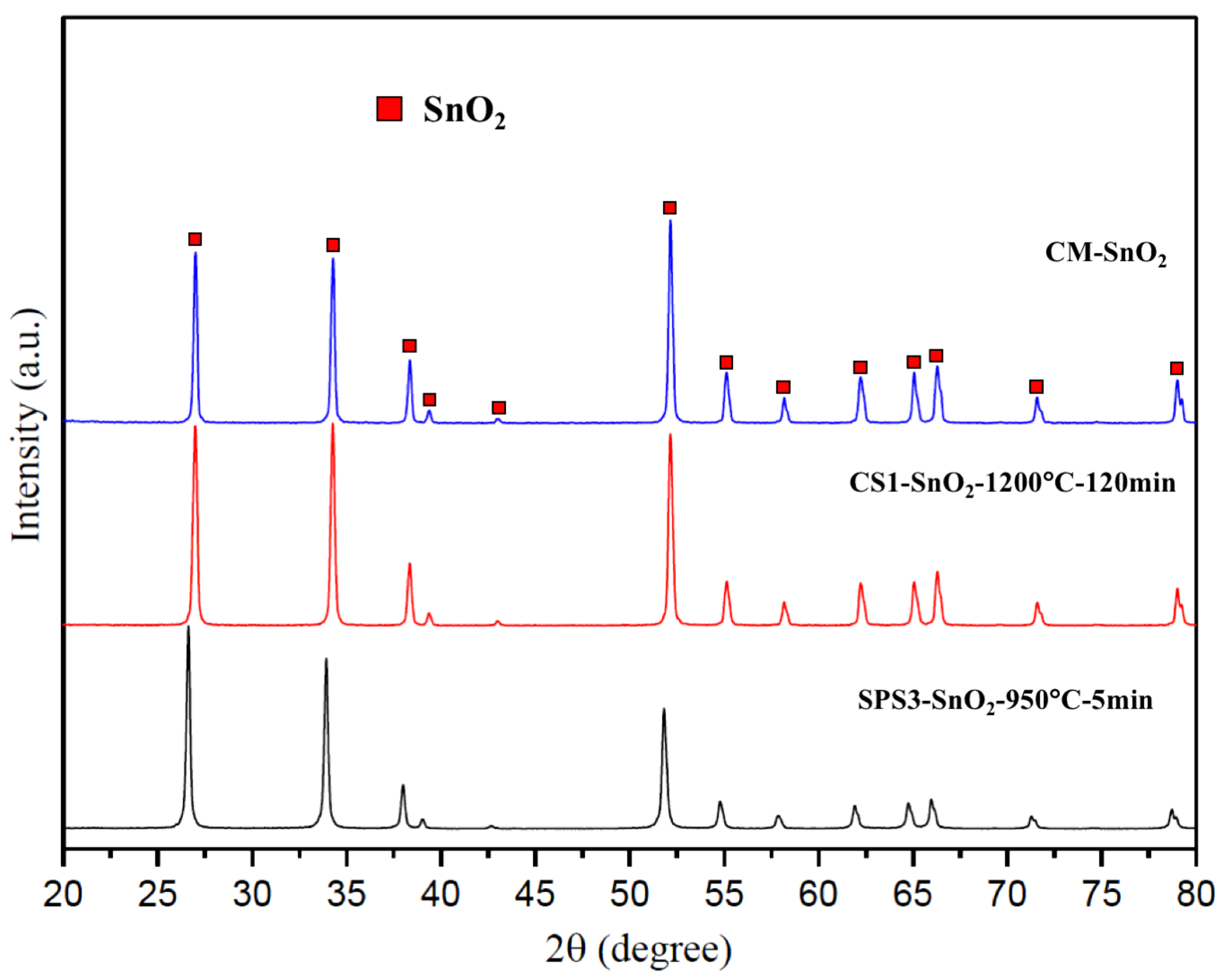

Figure 13

XRD patterns of SPS3-SnO2, CS1-SnO2 and CM-SnO2 